\title{
DISTRIBUTION OF GRAIN SIZES AND INTERNAL SURFACE AREA AND THEIR ROLE IN SNOW CHEMISTRY IN A SUB-ARCTIC SNOW COVER
}

by

\author{
H.B. Granberg
}

(Department of Geography, McGill University, 805 Sherbrooke St. West, Montreal, Québec H3A 2K6, Canada)

\section{ABSTRACT}

The variations in grain size and internal surface area in a seasonal snow cover have been studied near Schefferville, Quebec. Sieve analysis was applied to snow in very cold conditions and gave closely reproducible results.

The studies show that grain-size distributions vary greatly with depth but show a pattern that is closely repeatable between sites in similar environments and which is also closely repeatable from one year to the next. Different environments produce variations on the general pattern.

The measurements enable estimation of the internal surface area and its variations with depth in different snow covers. The effects of this variation in surface area on contaminants of the snow cover are discussed.

\section{INTRODUCTION}

A seasonal snow cover consists of a porous skeleton of ice which is a metamorphosed, sedimentary deposit of snow that originated in of ten widely different air masses. Different air masses impart different shapes and sizes to the snow crystals. They also add substances other than ice which are included in the growing snowflakes or adsorbed onto their surfaces. Falling snow generally has a very large surface area per unit mass and is an efficient scavenger of gases and particulates during its fall through the atmosphere.

Once the snowflakes have been deposited, their surface area per unit mass begins to diminish rapidly. However, for the first few days, their surface area per unit of mass is still very large which enables the snow cover to act as a filter when air passes through it (Gjessing 1977). Air motion through the near-surface layers occurs as a result of spatial variations in surface air pressure, induced by surface undulations and by the attenuation of air turbulence by the snow surface (Kimball and Lemon 1971, Granberg unpublished).

A variety of processes active in a cold snow cover lead to the redistribution of snowpack contaminants. The temperature gradient through the snow cover causes a general upward movement of mass while simultaneously a downward mass transfer occurs due to settling of the snowpack. The upward movement is accomplished by evaporation from warmer, lower, parts of the ice skeleton and condensation onto colder parts higher up in the snow cover. In this process concentration of contaminants may occur in those parts of the ice skeleton that evaporate. The contaminants follow the settling snow downwards while the upward mass movement, consisting of pure water, reduces the ratio of contaminants to pure ice in the upper parts of the snow cover.

Snow metamorphism results in a coarsening of the snow skeleton and a reduction in its surface area which causes a concentration of surficially adsorbed substances and may lead to rejection of gases that were adsorbed onto the snow crystals during their descent through the atmosphere. The reduction in surface area may also create concentration gradients and cause migration of surficially adsorbed substances on the surface of the snow skeleton, along gradients that are related to changes in the available surface area rather than to concentrations on a per unit volume or unit mass basis.

Spatial and temporal variations in grain sizes and surface area are important to our understanding of chemical and ecological aspects of the seasonal snow cover. They are also important to our understanding of the atmosphere in that they influence the chemical properties of the snow cover and thereby influence all inferences that are made about the atmosphere from observations of these properties. Despite the importance of the subject matter, very little information can be found about it in the literature.

This paper presents some results of grain-size and surface area estimations that were performed on snow covers in the vicinity of Schefferville, Quebec during late February in 1983 and 1984. In the low temperatures prevailing at Schefferville at that time of winter it is possible to use sieve analysis for grain-size determinations. Using a few simple assumptions regarding grain-shape factors it is then possible to make estimates of the internal surface area of the snow cover. In this paper no attempt has been made to assess accurately the area/mass ratios for different parts of the snow cover. The area estimates presented here should therefore only be regarded as crude approximations.

\section{METHODS}

\subsection{Snow sampling and sieve analysis}

Several of the snow profiles discussed in this paper were located in open woodland of approximately $25 \%$ crown coverage. One profile was located on a small bog and one profile was sited on an open, wind-swept lake (Knob Lake). A Swedish snow-density sampler (Granberg 1984, Granberg and Kingsbury in press) was used to collect rectangular slabs, one litre in volume, at vertical intervals of approximately $8 \mathrm{~cm}$ throughout the snow profile.

The samples were brought back to the laboratory where sieve analysis was performed on the distintegrated snow skeleton at temperatures of $-20^{\circ} \mathrm{C}$ or colder. The disintegration of the snow skeleton was accomplished by hand-kneading the sample bags until no lumps could be felt. This was done immediately before the sieving. Standard 8-inch sieves for soil analysis were used with an automated sieve shaker. The stack of sieves were $4,2,1$, $0.5, \quad 0.25$ and $0.125 \mathrm{~mm}$ mesh respectively and the agitation time was five minutes on an automated sieve shaker. The sieve contents were weighed on a Mettler 4000 electronic balance. Microphotographs of different size fractions were taken at intervals along the vertical profile in the 1983 survey of the "time-profile" site which is a specially prepared site for interannual surveys of snow-cover stratigraphy.

\subsection{Calculation of grain-surface area}

To calculate the internal surface area per unit volume of snow, the partial densities of individual size fractions $\mathrm{Dp}$ were first calculated by

$$
\mathrm{Dp}=\mathrm{Wp} / \mathrm{V} \text {, }
$$

where Wp is the weight of the particular grain-size fraction in grams and $V$ is the volume in cubic centimetres. 
The number of grains per unit volume of each sieve fraction is given by

$\mathrm{Np}=(\mathrm{Dp} / \mathrm{Di}) /(\mathrm{S}$ Sf $\mathrm{Vr})$,

where $\mathrm{Di}$ is the specific weight of ice in grams per cubic centimetre, $S \quad(=1)$ is the effective grain size for the grains in the particular sieve fraction and $S f(=1)$ is a shape factor representing the ratio of the actual grain mass to the mass $\mathrm{Vr}$ of a sphere of the same effective grain diameter. The effective grain diameter is a function of the grain diameter at the smallest cross-section of the grain, the shape of that cross-section and the distribution of sizes of these cross-sections in a given grain aggregate. In the following calculations, the mean of the upper and lower mesh sizes for each size fraction has been used as the effective grain diameter. There are some obvious shortcomings in using this approach but they are thought not to distort the results too seriously in this application.

The surface area Apv attributable to the particular grain size fraction is calculated by

$A p v=N p$ Af Ar,

where Af $(=1.5)$ is a factor accounting for the surface area of the grains as a decimal fraction of the area Ar of a sphere of the effective grain size.

The total surface area per unit volume $A v$ is obtained by summation of the partial areas of the individual grain-size fractions. To convert this value to surface area per unit weight of snow Aw the following relationship is used

$$
A w=A v / D \text {, }
$$

where $D$ is the density in grams per cubic centimetre of that snow layer.

\section{RESULTS}

\subsection{Repeatability of results}

To assess the repeatability of the results, a few of the samples were re-mixed and analyzed several times in succession. The repeatability was in all cases excellent, far better than is normally obtainable in soil analysis. Figure 1 shows results of a triple sieving which illustrates the close repeatability of the sieve analysis results.

The grain-size distributions from any given depth were always clearly distinguishable from the grain-size distributions obtained from any other depth within the particular snow profile. Figure 2 shows a typical set of

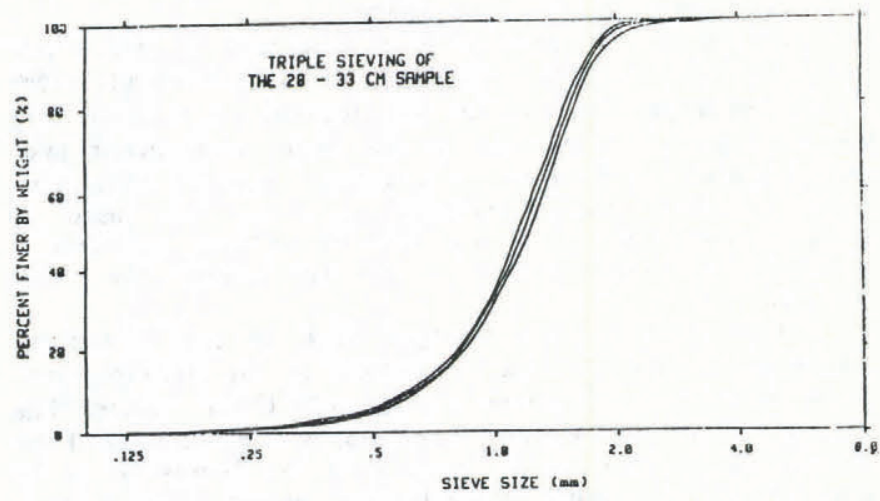

Fig.1. Result from repeat sieving of one sample.

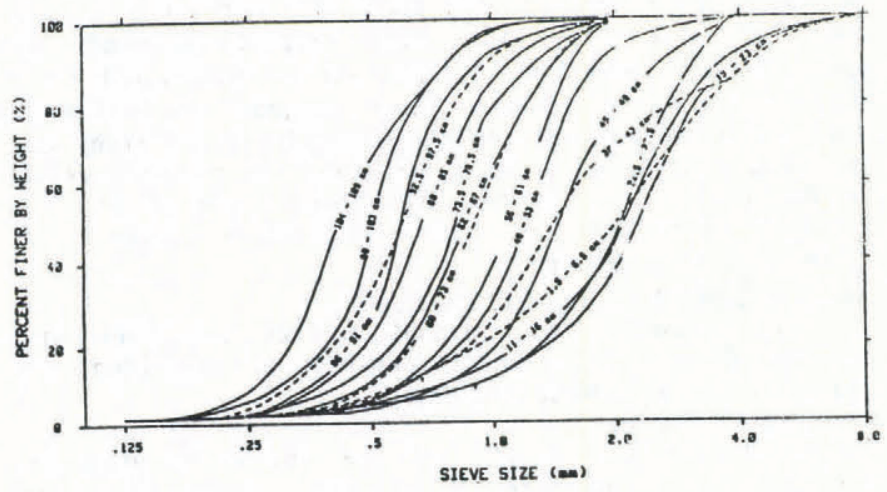

Fig.2. Grain-size distributions at time-profile site in 1983. grain-size distribution curves for one of the woodland sites.

3.2. Grain-size variations

In the following graphs the variations in grain-size distributions with depth in the snow cover have been displayed in per cent of total weight on the left side of the graph. The isolines represent different sieves and the space is proportional to the weight percentage of the total sample that did not pass through the particular sieve while the space to the right indicates the amount that did pass through it. The graph on the right shows vertical lines representing the depth interval spanned by each sample $(5 \mathrm{~cm})$ and the horizontal position of each such line indicates the density of that particular sample.

In the 1983 survey the plots of grain-size distributions with depth showed a close correspondence between different open woodland sites although some of the sites were located several kilometres away from the others. Figures 3,4 and 5 represent profiles obtained at different woodland sites in the Schefferville area. Although jags occur due to ice layers and occasional

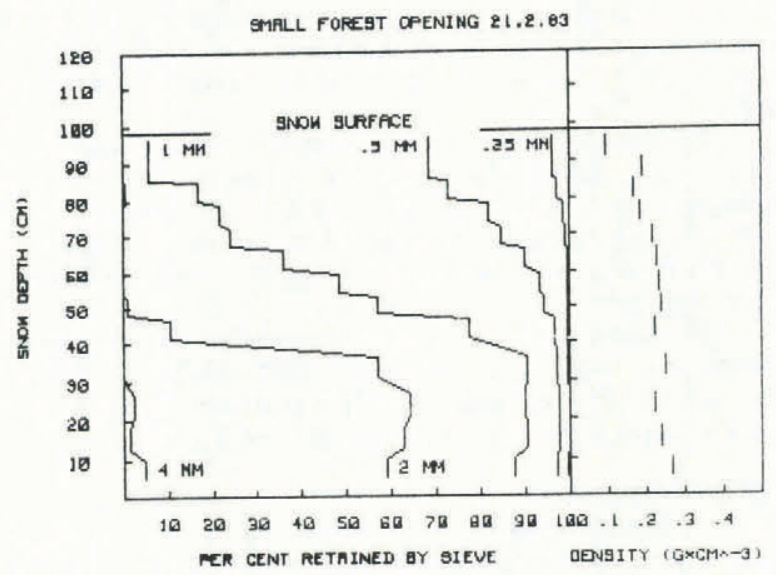

Fig.3. Open woodland site.

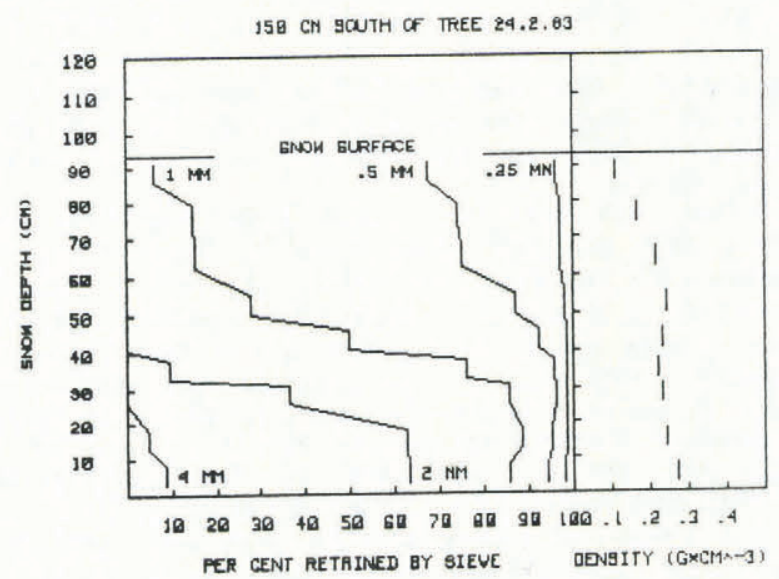

Fig.4. Open woodland site.

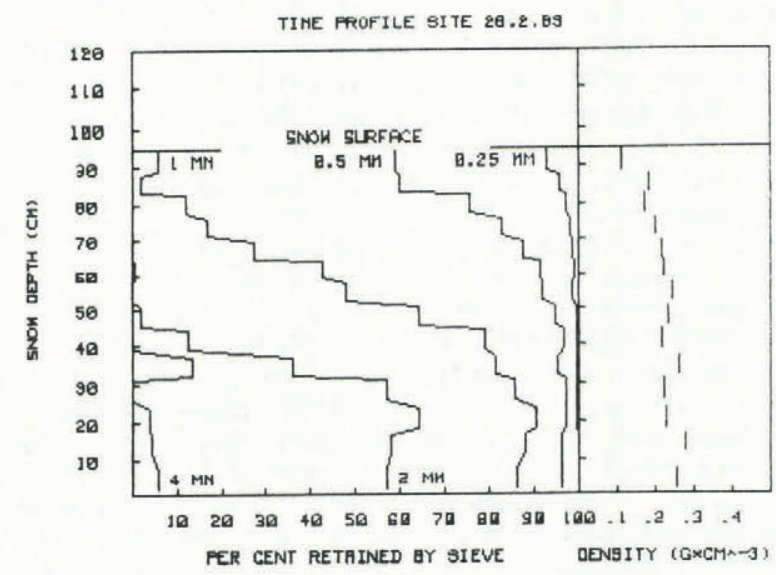

Fig.5. Time-profile site, 1983. 
inhomogeneities in some of the profiles, the similarity between the different profiles is striking.

There was a similar pattern of variations in grain-size with depth for the small bog and lake sites (Figs.6 and 7). Although the actual grain sizes and total depths differed in these cases the trends of change in grain-size with depth were similar. In all cases a peculiar, as yet unexplained, minimum in the finer size fractions occurred a few decimetres above the snow/ground interface rather than at the interface as might, at least intuitively, be expected.

The same general pattern was repeated in 1984 (Fig.8). The grain-size distributions show considerable similarity to those observed in 1983 and suggest a process which closely controls the relative proportions of different grain sizes at different depths.

3.3. Variations in surface area

The surface area per unit volume or weight of snow is shown by Figures 9 to 14 . In these figures the surface area per unit volume is plotted with a solid line while the surface area per unit weight is plotted with a

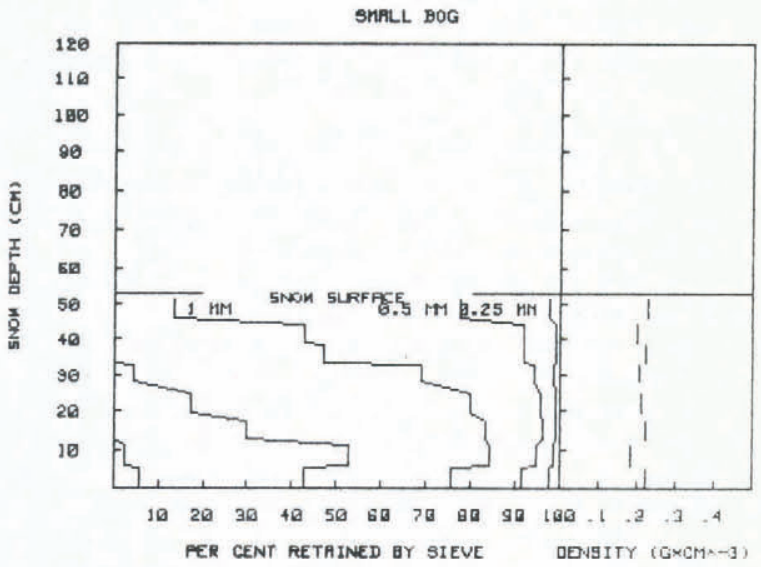

Fig.6. Small bog near Barney.

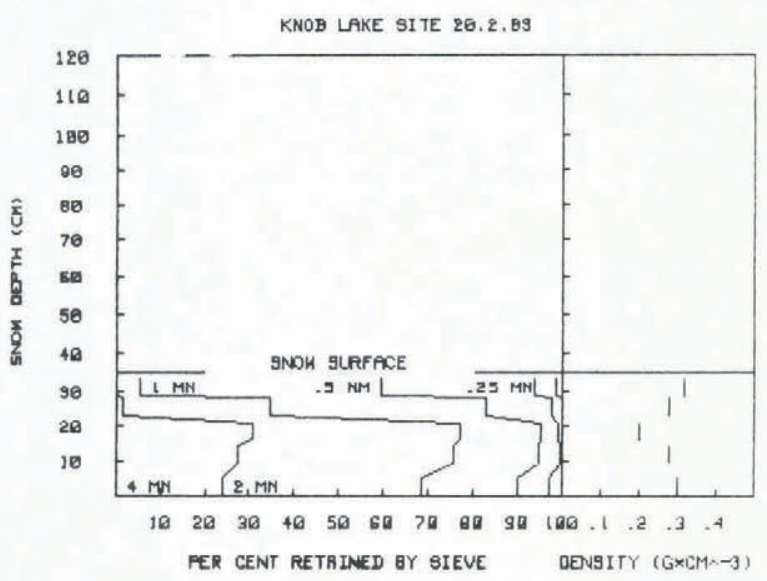

Fig.7. Site on Knob Lake.

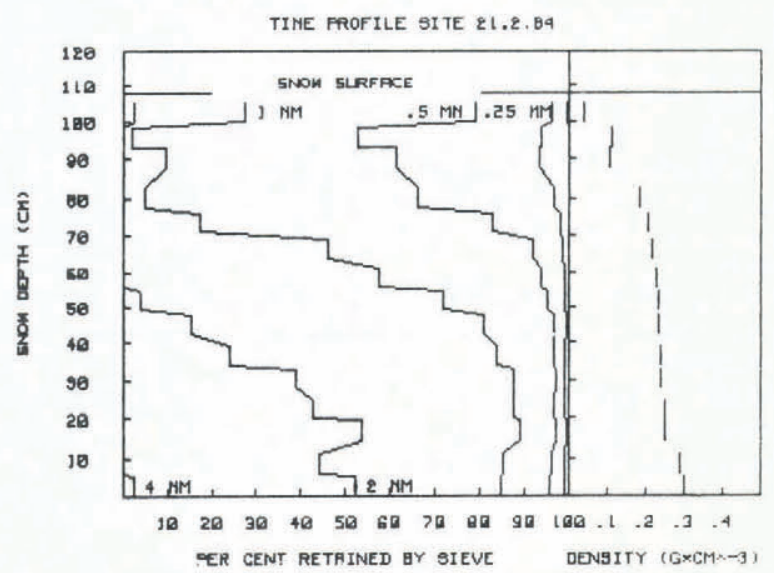

Fig.8. Time-profile site, 1984 dotted line. Four of the figures represent woodland sites (Figs.9 to 12) while Figures 13 and 14 represent a small sheltered bog and a lake, respectively.

The surface areas per unit volume and per unit weight exhibit relatively similar patterns for the three sites in open woodland as shown by Figures 9, 10 and 11 . The greatest variations occur in the near-surface layers where also the greatest uncertainties exist regarding the shape factor assumptions. In general, with the present assumptions, the surface area per cubic centimetre remains $<20 \mathrm{~cm}^{2}$ in the lowest 30 to $40 \mathrm{~cm}$ of the snow cover and is reasonably uniform throughout this layer. In fact, a slight minimum occurs 15 to $20 \mathrm{~cm}$ above the snow/ground interface. In the upper parts of the profiles, values are approaching $40 \mathrm{~cm}^{2}$ according to the present calculations. The true values are likely to be higher; the present set of assumptions would produce a conservative estimate.

The surface area per gram of snow varies from about $60 \mathrm{~cm}^{2}$ near the base to about three times that value near the surface. The value is constant or even declines somewhat with height in the lowest $30 \mathrm{~cm}$ of the snow cover.

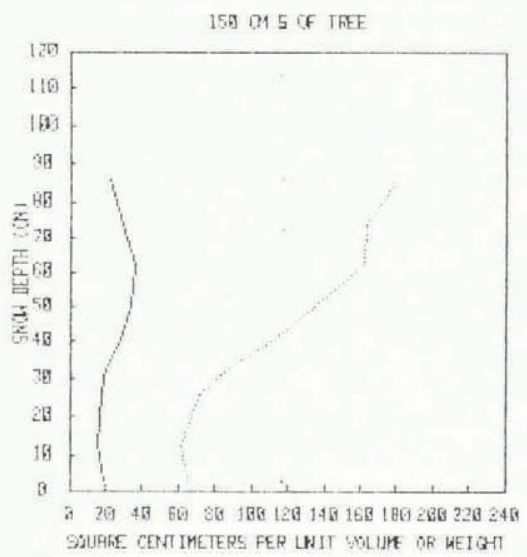

Fig.9. Woodland site.

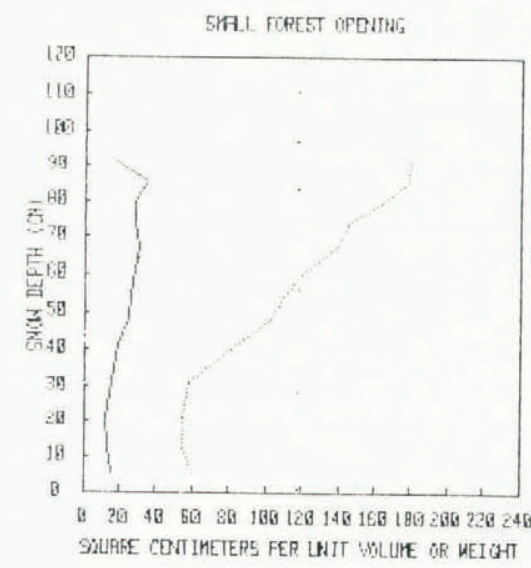

Fig.10. Woodland site.

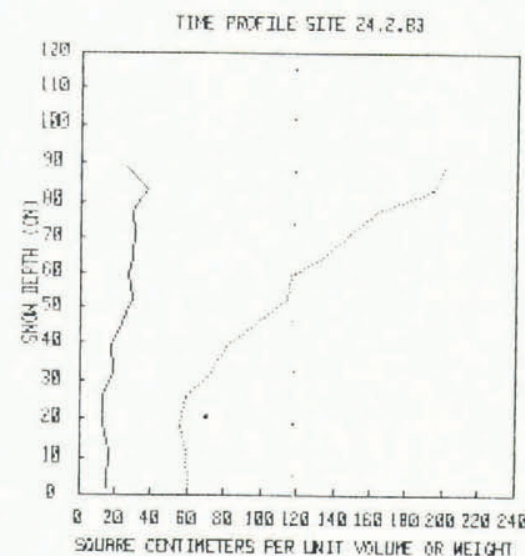

Fig.11. Time-profile site, 1983. 
TIIE PRTFILE. SIIE 2L.2.84

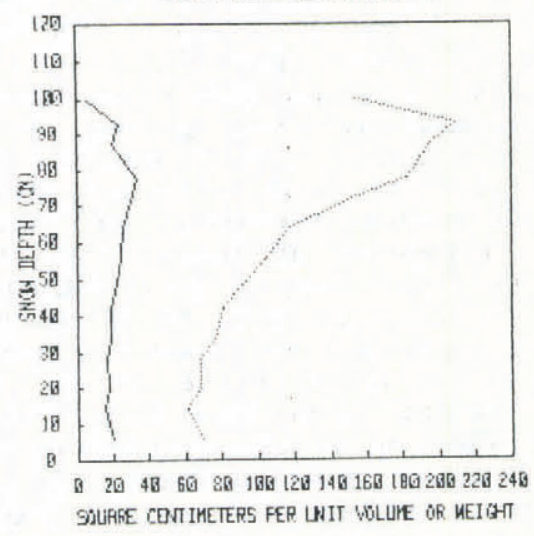

Fig.12. Time-profile site, 1984.

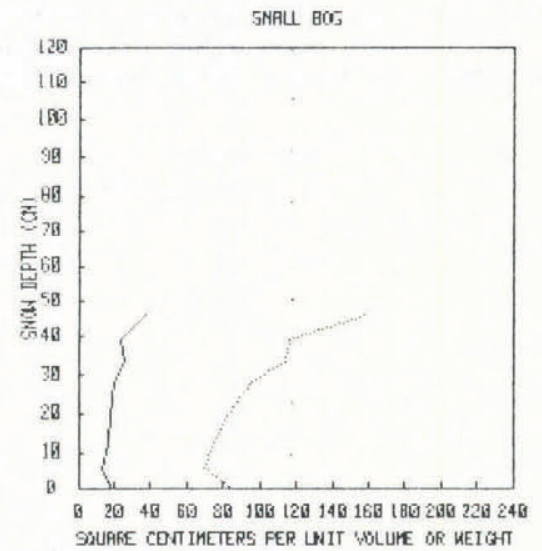

Fig.13. Site on small bog.

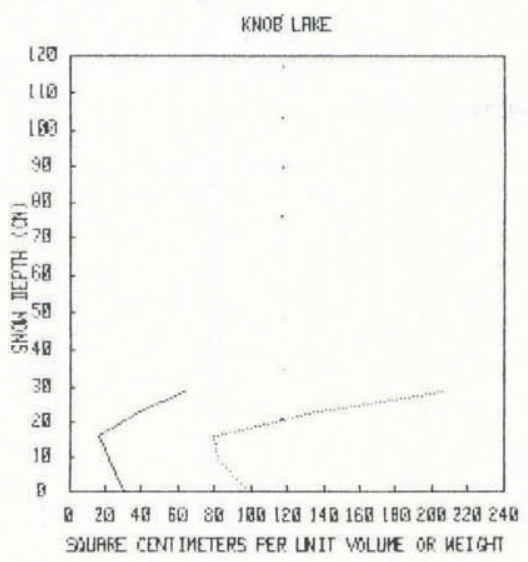

Fig.14. Site on Knob Lake.

There are no substantial differences between the areas per unit volume at the time-profile site in 1983 and 1984 respectively (Figs.11 and 12). The uppermost sample shows a very low value which can be ascribed to recent new snowfall in 1984. The stellar crystals from this snow fall were still intact when the analysis was performed which explains the fictitiously small surface area per unit volume. This layer obviously did not conform to the shape factor assumptions used in this study.

The bog profile (Fig.13) has, on account of the shallower snow, had a much steeper temperature gradient through it. There was an early winter melt in 1982-83 which incorporated the lowest part of the snow cover into a basal layer of solid ice. The snow cover was otherwise similar to the uppermost 50 to $60 \mathrm{~cm}$ of the woodland snow covers and was, similarly, unaffected by wind. The depth hoar was quite well developed in this snow cover as is shown by the small surface area per unit volume that prevails through most of the snow profile. The profile of surface area per gram is also different from those of the woodland sites. In its lower part the values are greater and in the upper part smaller than those for the forest sites.

As expected the wind-blown snow cover of Knob Lake shows a large surface area per unit volume (Fig.14). Its surface area is greater than for any of the other snow covers on the basis of both per unit volume and per unit weight.

\section{CONCLUSIONS AND RECOMMENDATIONS}

The present results show that different environments produce snow covers that differ considerably in terms of both grain-sizes and surface areas per unit volume or per unit weight. The results also show that there is a marked difference in these properties between the upper and lower layers of the snow cover in each of the different environments. With increasing depth below the snow surface there is a decrease in the surface area per unit weight by at least a factor of three. Since the present set of assumptions are intended to reflect snow grains of a well-rounded shape, the actual reduction in surface area that occurs after the initial deposition of snow can be many times greater.

The results shown here raise a set of new questions. First, the similarity between the changes in grain-size distribution with depth in the different woodland snow covers and the way in which these changes are repeated in different years provide an intriguing puzzle. What are the factors controlling the grain-size distributions and why is there a raised minimum in the finer grain-size fractions?

A second set of questions relate to the influence of the physical properties of the snow skeleton and changes in the snow skeleton on the substances residing within or on the surface of this skeleton. What migrations of surficially adsorbed substances can be caused by temporal changes in grain morphology? Which substances will be concentrated as a result of temperature gradient metamorphism? Will this concentration lead to reactions between different compounds? How does snow metasmorphism affect foreign matter in the snow cover?

The present data set cannot answer these questions. A time-profile study should be made of the way in which grain-size distributions and internal surface area changes throughout the winter season. The study should include an assessment of the morphological characteristics of the snow skeleton throughout the vertical profile and should include analyses of the chemical composition of the snow cover.

\section{ACKNOWLEDGEMENTS}

The author would like to thank Dr G J Irwin of the Vehicle Mobility Section, Defence Research Establishment Suffield for bringing to his attention the merits of sieve analysis of snow in cold-temperature conditions. Mr M Williams-Quill assisted in the field. The research was partially supported by DSS grant no. SU81-00094.

\section{REFERENCES}

Gjessing Y T 1977 The filtering effect of snow. International Association of Hydrological Sciences Publication 118 (General Assembly of Grenoble 1975 Isotopes and Impurities in Snow and Ice): 199-203

Granberg H B 1984 A report on the Swedish snow density sampler. Suffield, Alberta, Defence Research Establishment Suffield (Instrument Report 2)

Granberg H B Unpublished A field investigation of snowpack ventilation. (PhD thesis, McGill University, 1982)

Granberg H B, Kingsbury C M In press Tests of new snow density samplers. Proceedings of the Eastern Snow Conference

Kimball B A, Lemon E R 1971 Air turbulence effects upon soil gas exchange. Proceedings of the Soil Science Society of America 35: 16-21 